Cancer Letters Manuscript Title:

\title{
Tumor microenvironment and cancer therapy resistance
}

\author{
Yu Sun $1,2,3,4 *$
}

1. Key Lab of Stem Cell Biology, Institute of Health Sciences, Shanghai Institutes for Biological Sciences, Chinese Academy of Sciences and Shanghai Jiaotong University School of Medicine, , Shanghai, China 200031

2. Collaborative Innovation Center of Systems Biomedicine, Shanghai Jiaotong University School of Medicine, Shanghai, China 200240

3. VA Seattle Medical Center, Seattle, WA, USA 98108

4. University of Washington, Department of Medicine, Seattle, WA, USA 98195

*Corresponding author: Yu Sun, Key Laboratory of Stem Cell Biology, Institute of Health Sciences, Shanghai Institutes for Biological Sciences, Chinese Academy of Sciences and Shanghai Jiaotong University School of Medicine, 320 Yueyang Road, Biological Research Building A, Shanghai 200031, China. Tel: +86 21 54923302; Fax: +86 21 54923302; E-mail: $\underline{\text { sunyu@ } \text { sibs.ac.cn }}$

Keywords: tumor microenvironment; cancer therapy; acquired resistance; personalized medicine. 


\section{Abstract}

Innate resistance to various therapeutic interventions is a hallmark of cancer. In recent years, however, acquired resistance has emerged as a daunting challenge to anticancer treatments including chemotherapy, radiation and targeted therapy, which abolishes the efficacy of otherwise successful regimens. Cancer cells gain resistance through a variety of mechanisms in both primary and metastatic sites, involving cell intrinsic and extrinsic factors, but the latter often remains overlooked. Mounting evidence suggests critical roles played by the tumor microenvironment (TME) in multiple aspects of cancer progression particularly therapeutic resistance. The TME decreases drug penetration, confers proliferative and antiapoptotic advantages to surviving cells, facilitates resistance without causing genetic mutations and epigenetic changes, collectively modifying disease modality and distorting clinical indexes. Recent studies have set the baseline for future investigation on the intricate relationship between cancer resistance and the TME in pathological backgrounds. This review provides an updated outline of research advances in TME biology and highlights the prospect of targeting the TME as an essential strategy to overcome cancer resistance and improve therapeutic outcomes through precise intervention. In the long run, continued inputs into translational medicine remain highly desired to achieve durable responses in the current era of personalized clinical oncology. 


\section{Introduction}

The steps of tumor development implicate co-evolution of malignant cells and benign constituents of the surrounding stroma, while dynamic interactions between pathologically altered parenchyma and stroma within the TME represents a critical paradigm now considered among the typical hallmarks of cancer [1]. Histologically the association of infiltrating leukocytes and tumorigenesis was first described by Rudolf Virchow in 1863 to propose the potential relevance of chronic inflammation to neoplastic events [2]. Subsequently in 1889, Stephen Paget contributed a "seed and soil" concept to delineate the distinct patterns of recurrent metastatic sites in human breast cancer, and to plausibly interpret the tropism of tumor metastases to specific organs [3]. To date, plethora of studies have disclosed the unique aspects of the TME, with its mystical veil removed and diverse characteristics ascertained. It is increasingly evident that individual compartments of the TME do not stay as quiet bystanders, but significantly regulate tumor initiation, disease progression, metastatic development, and more importantly, therapeutic response. Among multiple TME-implicated activities, clinical response to therapies is the major factor that directly determines the long term fate of patients who undergo anticancer interventions. In this review, an updated picture of tumor-stroma interaction is depicted, with a particular emphasis on the capacity of the TME in modifying cancer sensitivity to therapeutic agents. An appropriate, thorough and in-depth understanding of the functional roles of TME in disease evolution is essential for rational design, reasonable innovation and successful translation of novel anticancer approaches to 
precise medicine with substantially improved clinical outcomes.

\section{The TME orchestrates disease progression and dominates therapeutic responses}

As a most lethal age-related pathology that imperils human health, cancer progresses with the surrounding TME to achieve continuous outgrowth and ensuing metastasis that correlates with the majority of cancer-related death [4]. Despite considerable advancements in therapeutic concepts and techniques, disease relapse with limited response remains a major challenge and confers poor prognosis in clinical oncology. Cancer resistance involves intrinsic mechanisms that are determined by pre-existing genetic and/or epigenetic properties of malignant cells including enhanced drug efflux, blunted apoptotic signaling, increased metabolic activities, loss of specific oncogenes, gain of stem cell plasticity and strengthened DNA damage repair machinery, all fueled by mutation-selective pressure that engenders clonal expansion and create tumor heterogeneity $[5,6]$. In contrast, extrinsic resistance of cancer cells driven by the TME represents a seemingly minor but essentially pivotal modality that substantially influences therapeutic efficacy.

First, the TME mediates innate resistance prior to cytotoxic treatment events, which is through regular mutual interactions between cancer cells and neighboring TME components. This force differs from inherent resistance which is based on original alterations at the genomic and/or epigenomic levels of cancer cells. Second, acquired resistance conferred by the TME usually emerges as a host adaptive response to pharmacological insults. Specifically, the TME-provoked resistance generates profound impacts to local disease foci and shapes cancer evolution path under varying 
treatment pressures in clinical settings.

\section{Cancer-associated fibroblasts}

In solid tissues, fibroblasts constitute the structural framework and maintain physiological homeostasis as a predominant mesenchymal lineage. However, cancer-associated fibroblast (CAFs) are functionally distinct from their normal counterparts and frequently demonstrate pathological relevance. In the microenvironment milieu, normal fibroblasts can be transformed into CAFs once stimulated by local tissue-derived proteins such as fibroblast growth factor (FGF), monocyte chemotactic protein 1 (MCP-1), platelet-derived growth factor (PDGF), tissue inhibitor of metalloproteinase 1 (TIMP-1) and tumor transforming growth factor $\beta$ (TGF- $\beta$ ) $[7,8]$. Besides, miR-27a/b-transfected normal fibroblasts show increased expression of TGF- $\beta$ and $\alpha$-smooth muscle actin ( $\alpha$-SMA, a marker of $\mathrm{CAF}$ ), changes that correlate with reduced chemosensitivity of esophageal cancer cells to cisplatin [9]. Despite the tumor-suppressive capacity in certain malignancies including pancreatic ductal adenocarcinoma (PDA) [10, 11], CAFs exhibit aggressive proliferation, augmented extracellular matrix (ECM) deposition, enhanced cytokine synthesis/secretion (for instance, FGF7; hepatocyte growth factor (HGF); interleukin 6 (IL-6); PDGF; stromal cell-derived factor 1, (SDF-1); vascular endothelial growth factor (VEGF)) [5], a unique stromal phenotype characterized with a chemoresistance-triggering secretome that can be abolished upon mTOR/4E-BP1 translation pathway blockade [12]. 
Following activation in the TME, CAFs generate proinflammatory factors that promote tumor progression in an NF- $\mathrm{BB}$-dependent manner, drive leukocyte infiltration, stimulating angiogenesis and vascular permeability [13-15]. Primary tumors select for bone metastatic seeds in the TME based on the interaction between Src pathway-activated cancer cells and chemokine C-X-C motif ligand 12 (CXCL12)/insulin-like growth factor 1 (IGF1)-secreting CAFs, indicating the evolution of metastatic traits in a primary foci and the distant metastases [16].

In tamoxifen-resistant breast tumors, $\mathrm{G}$ protein-coupled estrogen receptor (GPER)/ epidermal growth factor receptor (EGFR)/extracellular regulated protein kinase (ERK) signaling enhances $\beta 1$-integrin expression and activates downstream kinases, contributing to CAF-induced cell migration [17]. Moreover, downstream kinases of $\beta 1$-integrin including focal adhesion kinase, Src and AKT are activated in resistant cells, potentially involved in the interaction between cancer cells and CAFs [17], highlighting the persistent tumor-stroma communication in a biologically dynamic TME. More importantly, CAFs establish a synergistic relationship with cancer cells, contributing to their malignancy and therapeutic resistance. In clinics, standard chemotherapy can phenotypically and metabolically change stromal fibroblasts into CAFs, leading to the emergence of a highly glycolytic, autophagic and pro-inflammatory microenvironment, which subsequently activates stemness (Sonic hedgehog/GLI signaling), antioxidant response and interferon-engaged signaling in nearby cancer cells [18]. 


\section{Vasculature system}

The tumor vascular network derives from new vessels, through co-option and modification of mature vessels, or via differentiation of endothelial precursors from bone marrow, each contributing to vascular development and heterogeneity [5]. Vessel formation involves remodeling of pre-existing vascular basement membranes, and the pattern varies depending on the tissue type. Although a functional vasculature is vital for both tumor survival and metastatic progression by supplying oxygen and nutrients, poorly organized tumor vasculatures cause emergence of hypoxia and limited growth factor feeding. Co-operation of several cell types in the TME, including endothelial cells, pericytes and bone marrow-derived precursor cells is fundamental for tumor vascularization, although such synergism is often modulated by hypoxia $[19,20]$.

Spatial distance from vasculatures to tumor foci generates an infiltration gradient associated with drug distribution to cancer cells within the tissue, while microvessel density (MVD) is a significant prognostic factor for clinical outcome in malignancies including breast, liver, lung and lower lip squamous cell carcinoma (LLSCC) [21-24]. Mesenchymal stem cells (MSCs), tumor-associated macrophages (TAMs) and CAFs, all contribute to tumor vascularization by secreting a variety of angiogenesis-related ligands into the TME. Particularly, increased expression of the pro-angiogenic factor VEGFA is correlated with worse prognosis in metastatic colorectal, lung and renal 
cell cancers [25].

Tumor associated endothelial cells (TECs) differ from normal endothelial cells (NECs) in multiple aspects, and exhibit distinct gene expression signatures. Particularly, chemokine CXC motif ligand receptor (CXCR)7 is upregulation in TECs and promotes angiogenesis in the TME via ERK1/2 phosphorylation [26]. Interestingly, CXCL12, a ligand of CXCR7, is present in conditioned medium from TECs, but not NECs. The CXCL12-CXCR7 autocrine loop influences TEC-associated proangiogenesis, tumor growth, lung metastasis and resistance, thus is considered for antiangiogenesis-purposed therapies that specifically target tumor blood vessels [26].

Recently, increasing evidence indicates that resistance to VEGF receptor inhibition arises from hypoxia-driven residual VEGF and other proangiogenic factors, thus combinations of agents targeting these factors are hypothesized to improve treatment outcomes relative to single VEGF pathway blockade alone. However, sorafenib, temsirolimus, and bevacizumab administered in synergistic manners did not significantly improve median progression-free survival when compared with bevacizumab monotherapy, although further investigation is being performed to determine the resistance mechanisms [27].

\section{Extracellular matrix}

The ECM is produced by multiple TME cell types and weaves an intricate fiber 
network not only providing structural support but regulating cellular activities [28]. In early life stages the ECM prevents cancer initiation as a safeguard, while at a later stage it actively increases pathological incidence particularly tumorigenesis [29]. TME-associated ECM essentially differs from that of the normal tissue, serving as a basic scaffold for cancer cell invasion driven by chemotaxis [30]. Interplay between cancer cells and ECM elements is dynamic and goes far beyond spatial contact. In breast cancer, malignant cell attachment to ECM alters their polarization and causes resistance to etoposide-induced apoptosis [31]. Specifically, cell adhesion-mediated drug resistance (CAM-DR) depends on association of integrin to ECM components including fibronectin, collagen and laminin [6]. Integrin-implicated cancer resistance is not limited to chemotherapies, but applies to radiation and targeted therapies by attenuating activities of receptor tyrosine kinases (RTKs) such as EGFR [32, 33] . Enhanced ECM biosynthesis and elevated collagen fiber crosslinking in the reactive stroma further enables cancer progression through integrin signaling [34]. Of note, desmoplastic stroma is a physical barrier for chemotherapeutic agent delivery and influences tumor vascular architecture [35].

According to the ECM composition, patients including those with breast neoplasia can be stratified into several classes and predicted with distinct clinical outcomes [36]. Tumors with increased protease inhibitor expression in the ECM are associated with optimistic prognosis, but those with upregulated integrins and matrix metallopeptidases (MMPs) correlate with poor prognosis with recurrence possibility. To this end, a bioinformatic approach to predict the in silico "matrisome" defined as 
the ensemble of ECM proteins and associated factors was developed, which revealed that primary foci of diverse metastatic potential differ in their composition of both tumor- and stroma-derived ECM components [37]. Therefore, targeting the ECM that is structurally adjacent and functionally linked to tumors may provide an extra option for therapeutic intervention.

However, taking into account of influences exerted by the ECM and three-dimensional (3D) microenvironment, the TME control of breast cancer responses to doxorubicin within a 3D laminin-rich ECM culture model system was differently documented. Chemotherapy-induced activation of autophagy was compromised in the 3D matrix with impaired expression of p53 and DRAM-1, the latter a p53-dependent autophagy activator upregulated in response to DNA damage, implying functional link between doxorubicin-associated cytotoxicity and hindered autophagy induction via the p53-DRAM-autophagy axis [38]. In contrast, high levels of EGF-like repeats and discoidin I-like domains 3 (EDIL3), an autocrine ECM protein with angiogenic and anti-inflammatory effects, contribute to a receptive TME for the survival of detached hepatocellular carcinoma (HCC) cells and involve in cancer cell dissemination, suggesting that agents disrupting EDIL3 ligation to cell surface receptors hold potential therapeutic value by enhancing anoikis in tumors [39].

Immune cells 
Under physiological conditions, an intact immune system functionally mounts anti-tumor responses, but mechanisms of immune suppression in pathological settings can prevent this process thereby promoting disease progression. Both positive and negative checkpoint signals are involved in $\mathrm{T}$ cell activation as host response to prevent damage and minimize autoimmunity. Cytotoxic $\mathrm{T}$ cells in the TME are activated through continuous engagement of inhibitory cell surface receptors, including cytotoxic T lymphocyte associated antigen 4 (CTLA-4) and programmed death 1 (PD-1) receptor, through ligand overexpression [40]. Alternatively, anti-tumor $\mathrm{T}$ cell responses are suppressed within an immunosuppressive milieu, as tumorigenesis induces expansion of a myeloid-derived suppressor cell (MDSC) population that comprises early myeloid progenitors, immature dendritic cells (DCs), neutrophils and monocytes, a process that implicates endocrine communication with the immune system through enhanced secretion of chemokines including granulocyte-macrophage colony stimulating factor (GM-CSF) and granulocyte colony stimulating factor (G-CSF) [41, 42]. Tumor-induced recruitment of immunosuppressive myeloid lineages not only diminishes adaptive immunity, but fosters angiogenesis through production of basic fibroblast growth factor (bFGF), TGF- $\beta$ and VEGFA [43]. MDSCs also inhibit effector T cell proliferation, activation and migration, while enhancing immunosuppressive regulatory T cell expansion [44].

In addition to myeloid cells, B cells can advance tumor progression by mounting chronic immune response, inflammatory mast cells are involved in tumorigenesis and angiogenesis, while TAMs are functionally plastic and can adjust their polarization to 
motivate cancer cells and interfere with innate immunity [5]. Data from TME analysis indicates that angiogenesis, hypoxia and high TAM content relative to cytotoxic T cell number correlate with a worse outcome of breast tumors, although the overall stromal signature derived from patient biopsies predicts outcome independently of tumor subtypes [45]. First, infiltrating immune cells particularly TAMs can modulate the response of malignant cells to various anticancer therapies. A recent study demonstrated that TAMs mediate resistance to gemcitabine by overexpression of cytidine deaminase, which inactivate gemcitabine in pancreatic ductal cancer cells [46]. Increased secretion of IL-10 by TAMs is responsible for drug resistance in breast cancer, a case associated with elevated Bcl-2 expression and upregulation of STAT3 signaling, while neutralizing antibody to TAM-derived IL-10 can reverse such resistance [47]. Second, certain immune cell functions can be restrained to enhance therapeutic response. For instance, TAMs produce IL-6, which allows expansion of CD44(+) cancer stem cells (CSCs) in HCC patients and correlates with recurrence after therapy [48]. Blockade of IL-6 signaling with tocilizumab, a drug approved by the Food and Drug Administration (FDA) for rheumatoid arthritis, effectively inhibited TAM-stimulated resistance of CD44(+) cells. Production of chemokine C-C motif ligand 2 (CCL2) and colony-stimulating factor 1 (CSF-1) is critical for both sustaining TAM numbers and recruiting TAMs to tumor foci, while agents targeting such ligands and/or their receptors effectively improved therapeutic outcomes in preclinical models [49].

In addition, MDSCs promote tumor progression through inhibiting $\mathrm{T}$ cell 
immunity thereby promoting malignant cell proliferation, migration and invasion, collectively contributing to tumor resistance. Nevertheless, therapeutic attempts to target MDSCs are hindered by their heterogeneity, plasticity, and tolerance to various chemotherapeutic agents. It is reported that tumor-infiltrating MDSCs have increased fatty acid uptake and activated fatty acid oxidation (FAO), accompanied by enhanced mitochondrial mass, key FAO enzymes, and oxygen consumption. In contrast to FAO inhibition alone which delays tumor growth in a $\mathrm{T}$ cell-dependent manner, FAO suppression combined with low-dose chemotherapy thoroughly inhibited MDSC-associated immunosuppression, with significantly improved anti-tumor effects $[50]$.

\section{TME-derived exosomes}

Exosomes originate in large multivescular bodies (MVBs), form in the extracellular milieu upon MVB fusion with the plasma membrane, share the same topology as a cell and harbor a large pool of biologically active components [51]. In the TME, exosomes are secreted by diverse cell types and circulate with body fluid in forms of blood, urine, saliva, ascitic fluid, and amniotic fluid [52].

Despite the presence of typical paracrine mechanisms that play critical roles in cancer-stroma communication, exosome shedding has recently emerged as another mode of TME-implicated pathologies. For example, melanoma-released exosomes increased both growth and metastasis of primary tumors and expansion of bone marrow derived cells (BMDCs) toward a pro-metastatic phenotype through the 
receptor tyrosine kinase MET-mediated signaling, effects significantly impaired by inhibition of exosomes [53]. Exosome of cancer cell origin can functionally trap therapeutic antibodies such as rituximab and trastuzumab, eventually compromising immunotherapy efficacy $[54,55]$. Fibroblast-secreted exosomes enhance protrusion and motility of breast cancer cells through Wnt-planar cell polarity (PCP) signaling, while co-implantation of cancer cells and fibroblasts promotes metastasis that is associated with PCP activities and CD81 in fibroblast exosomes [56]. Noncoding RNAs and transposable elements in stromal exosomes trigger retinoic acid inducible gene 1 (RIG-I), a pattern recognition receptor, to activate signal transducer and activator of transcription 1 (STAT1)-associated antiviral signaling, engage NOTCH3 pathway and expand breast cancer (BCa) subpopulations adept at countering treatments and acquiring tumor-initiating ability [57]. Although soluble factors in natural killer (NK) cell-derived exosomes induce tumor cytotoxicity and activate immune cells, they do not disrupt resting immune cells, indicating special targeting of activated cells by these exosomes [58]. Dendritic cell (DC)-released exosomes, termed dexosomes, are in clinical trials to evaluate their potential as a cancer vaccine, an investigation encouraged by the fact that dexosome immunization induce CD8+ cytotoxic T cells and inhibit tumor growth [59].

Besides protein factors delivered by exosomes, microRNAs (miRNAs) released from these extracellular particles further contribute to the development of drug resistance in the context of the TME. Recent data indicate a unique role of exosomic miR-21 and miR-155 in the cross-talk between neuroblastoma cells and human 
monocytes, which involves the resistance to chemotherapy through a novel exosomic miR-21/toll-like receptor (TLR)8-NF-кB/exоsomic miR-155/telomeric repeat binding factor (TERF)1 signaling pathway [60]. In prostate cancer, exosomal miR-34 regulates Bcl-2, thereby potentially influencing response to docetaxel. More importantly, four of such prostate-specific miRNAs (miR-598, miR-34a, miR-146a, miR-148a) are predicted to modulate a range of common mRNA targets, two of which (SNCA and SCL7A5) exhibit a close relationship with prostate cancer progression and poor prognosis [61]. Exosomic miRNAs are produced by multiple cell types, including dendritic cells, lymphocytes, and cancer cells, pathologically playing an important role in cell-to-cell communication, thus are being investigated as significant prognostic and diagnostic biomarkers [62].

Overall, the functional relevance of TME in altering tumor phenotypes and shaping disease evolution is supported by rising lines of experimental and clinical evidence, further highlighting the intricate profiles of TME structure and function that entered the spotlight of targeted therapies (Figure 1). Although there are reports regarding the positive role of local microenvironments in sensitizing tumors to treatments $[10,11]$, recent studies revealed the capability of TME in distorting outcomes of non-conventional interventions including targeted regimens. Kinase inhibitors to BRAF, ALK or EGFR induce a complicated network composed of secreted factors in human and mouse melanoma and lung cancer [63]. The therapy-induced secretome (TIS) promotes dissemination and metastasis of drug-resistance clones and contribute to incomplete disease regression, but tumors are 
susceptible to combination agents that inhibit both BRAF and PI3K/Akt/mTOR intracellular signaling pathways. Thus, the long term understanding of anticancer therapies that plausibly target only malignant cell populations is insufficient, which should be well updated with the rapidly blooming discoveries in cancer biology and accelerated advances in medical oncology.

\section{Treatment-activated TME confers acquired resistance and poses a significant challenge to interventional effectiveness}

\section{Damage responses of the TME offset therapy-enforced tumor regression}

First introduced into clinics in 1940s for preliminary uses of nitrogen mustards and antifolate drugs, chemotherapy constitutes the mainstay of modern anticancer regimes and demonstrated remarkable potency in controlling malignancies including leukemia, lymphoma and most solid tumors [64]. However, the technical limitations of chemotherapy discovered by the early researchers still remain, and the major downside has been the low efficiency in distinguishing between normal and cancer cells. Exposure of patients to chemotherapy or radiation, a genotoxic approach sharing similar treatment principles in oncology, inevitably triggers in vivo damage responses that significantly compromise therapeutic outcomes [65].

Cellular senescence occurs among normal cells in response to oncogenic overexpression (oncogene-induced senescence, OIS) or telomeric attrition (replicative senescence, RS), serving as a physiological checkpoint for cell cycle progression and prevent carcinogenesis. Importantly, senescent cells also exhibit another visage characterized with production of a plethora of cytokines, chemokines, proteases and 
growth factors, a signature termed the senescence-associated secretory phenotype (SASP) or the senescence messaging secretome (SMS) [66, 67]. While considered as an evolutionarily conserved program that regulates tissue homeostasis and regeneration at early life stage, SASP generates multiple deleterious effects in aging individuals [68]. Despite the cell-autonomous function of certain SASP factors such as IL-6 and IL-8 in reinforcing the senescence state, diverse SASP effectors act as cell non-autonomous molecules that degrade basement membrane, promote cancer resistance, enhance metastatic potential, together accelerating tumorigenic progression $[69,70]$.

Genotoxicity delivered by chemotherapy and radiation not only destroy the mass of tumors, but attack benign compartments in the TME. Treatment response correlates with activation of a DNA damage secretory program (DDSP) in stromal cells, as is recently identified by multiple studies. Specifically, persistent DNA damage signaling triggers senescence-associated inflammatory cytokine production, while distinct nuclear structures in damaged fibroblasts sustain treatment-induced senescence growth arrest $[71,72]$. Besides typical senescence attributes that are consistent with SASP features, the TME in prostate, breast and ovarian cancer patients displayed remarkable upregulation of WNT16B upon neoadjuvant or classical chemotherapy, while NF- $\kappa \mathrm{B}$ appeared as a key signaling node that actively mediates WNT16B biosynthesis [73]. Cell culture assays and tumor xenograft models demonstrated the protective effect of stroma-derived WNT16B, indicating that WNT16B produced by the TME attenuates cancer cell apoptosis caused by genotoxicity, and confers tumor 
insensitivity to therapeutic agents through activation of a stroma-intense secretory phenotype. Phenotypes driven by the DDSP are distinct and the associated secretion is robust, with many extracellular proteins overexpressed by ten-fold or even higher (for instance, MMP1 by 76-fold and WNT16B by 34-fold, respectively), and the effects are supposed to be chronical as evidenced by effector secretion in TME niches of clinical specimens collected even months (or years) after radical surgery of cancer patients $[6,73]$.

In parallel, soluble factors from the TME can modulate survival of lymphoma cells following administration of genotoxic drugs. IL-6 and Timp-1 from endothelial cells of the thymus create a chemoresistance milieu, promoting the survival and expansion of cancer cells remaining in the local microenvironments as minimal residual disease (MRD), and priming for eventual tumor relapse [74]. Therefore, resident benign cells in the TME respond to genotoxic stress by activating a paracrine secretory program, which can be coopted by malignant cells to survive frontline chemotherapy. Although such a response is named acute stress-associated phenotype (ASAP) as distinct from SASP which upon DNA damage develops gradually within 7 to 10 days after establishment of senescence markers, the process is essentially covered by the concept of DDSP, a more general term that can be exploited to adjust therapeutic parameters such as fine tuning of metronomic chemotherapy [75].

In contrast to organs that comprise mostly well-differentiated cell lineages, the bone marrow is a significant source enriched with both stem cells and varying progenies beyond myeloid components mobilized and recruited to the TME in 
response to therapies. Upon cisplatin-exerted damage, MSCs in the bone marrow secrete polyunsaturated fatty acids, which promote resistance to various agents and even act at a systemic level [76]. Administration of antiangiogenic agents including doxorubicin, 5-fluorouracil and paclitaxel causes the bone marrow to generate circulating endothelial cells that are homed to tumor sites [77]. Interestingly, antibodies that target VEGF receptor 2 (VEGFR2) or SDF-1 $\alpha$ abolished such recruitment and enhanced treatment efficacy, a case yet not reproducible by gemcitabine-involved combination therapy. Further, a protective niche was recently identified within the bone marrow, created by cancer propagating cells (CPCs) of leukemia following cytarabine and daunorubicin treatment [78]. The "refuge" niche evolves during therapeutic intervention, while recruited mesenchymal cells secreted chemokine C-C motif ligand 3 (CCL3) and growth differentiation factor 15 (GDF15) that actively built a therapy-induced shield, transitioned from Nestin+ cells to alpha smooth muscle actin (a-SMA)+ cells under the influence of TGF- $\beta$ and finally turned into fiber residues. Similarly, a lymphatic niche is present in melanoma and permits CD133+ tumor initiating cell (TIC) survival, accumulation and metastasis after dacarbazine administration, while radiation-damaged TME generates a stem cell niche and confers resistance to glioma cells that reside preferentially in specific sites [79, 80].

Modified differentiation and immune responses in the TME decrease therapeutic outcomes

Polarized epithelial cells can convert to motile mesenchymal cells before in vivo 
relocation, a process termed the epithelial to mesenchymal transition (EMT). Although frequently delineating cellular plasticity in tissue homeostasis and organ developments, EMT represents a typical cell-intrinsic mechanism that allows development of cancer resistance, and studies have proved that damage-induced expression of soluble factors in the TME can promote such a phenotypic switch of cancer cells to affect therapeutic outcome $[66,73]$. Both altered microRNA expression and abnormal intracellular signaling are linked with EMT, and a "signature" of 30 experimentally validated microRNAs and genes is recently reported that images the crosstalk between paracrine TGF- $\beta$, Notch, and Wnt released from TME resident cells during EMT and reinforce their regulation of epithelial plasticity in tumors [81]. In human breast tumors, MSC-activated malignant cells are enriched in EMT markers and phenotypes upon engagement of lysyl oxidase (LOX) via the CD44-Twist signaling axis, while a biological crosstalk between MSC-driven EMT and CSC machineries is suggestive of independent outside-in signaling axes that regulate miR-199a in multiple MSC-activated breast cancer cells [82].

Interestingly, melanoma cells can dedifferentiate in a mouse model upon adoptive cell transfer (ACT), resulting in melanocytic antigen loss and resistance to ensuing ACT cycles, a phenomenon mediated by tumor necrosis factor alpha (TNF- a) released by tumor-infiltrating $\mathrm{T}$ cells and macrophages in the TME [83]. Several TME-released cytokines including TNF-a mediate mesenchymal differentiation through NF-kB in glioblastoma, eventually causing radioresistance [84]. In addition, macrophages can be programed by chemotherapies including platinum analogs, which 
induce an M1-M2 transition in the TME, while low-dose irradiation promoting an iNOS+/M1 phenotype that orchestrate $\mathrm{T}$ cell immunotherapy toward an immunosuppressive state allows the recruitment of cytotoxic T cells in the tumor [85, 86]. Hypoxia-primed breast cancer cells chemoattract and polarize macrophages to pro-angiogenic M2-polarized subtype via Eotaxin and Oncostatin M [87]. However, blockade of Eotaxin/Oncostatin M not only prevented emergence of the M2-polarized phenotype and retarded tumor progression in 4T1/BALB/c-syngenic mouse model of breast-cancer but enhanced the efficacy of the antiangiogenic agent Bevacizumab, implying therapies targeting these cytokines are optimal for tumors that are refractory to anti-angiogenic drugs.

Collectively, damage responses of resident lineages in the TME alter differential status of cancer cells and rewire immune cell signaling to significantly compromise therapeutic efficacy. Successfully unraveling the complexity and exploiting the mechanisms represents an optimal avenue to minimize resistance acquired from a treatment-remodeled TME. To date, it is increasingly evident that durable responses will indeed optimally result from novel regimens that both target cancer cells and manipulate the TME components. To this end, targeted agents to control the impact of stromal cell types are now developed in multiple pipelines and ongoing clinical trials allow one to envisage a clear scenario (Table 1).

\section{Overcoming challenges of personalized cancer therapy requires translation of biomedical insights into the clinic}

Implications of personalized cancer therapy in an era of precision medicine 
Personalized cancer therapy (PCT) takes advantage of informative clues from the tumor and its microenvironment, together with distinct conditions of the patient, to tailor therapeutic regimes and treat the disease more effectively with less toxicity. PCT delivers a similar concept with "individualized cancer therapy" (ICT) that aims to design strategies for a person diagnosed with cancer, through covering drug sensitivity testing, cancer biomarkers and bioinformatics detection, pharmacogenetics, individualized antimetastatic therapy, drug combinations, assistant chemotherapy, cost-effectiveness consideration, and guidelines for utilization/reimbursement of molecular diagnosis.

A major obstacle to controlling cancer progression in patients is the inappropriate selection and administration of anticancer agents. Researchers and clinicians are now beginning to focus on PCT, to improve therapeutic quality and outcomes by prescribing the most appropriate and effective drugs. Using genetic, molecular, and bioinformatics data and modern experimental techniques, known oncogenes can be detected more easily than ever before. A good case in point is, the average speed of genetic sequencing has increased substantially since the completion of human genome project (HGP). Recently, a 22-marker panel genomic classifier (GC) validated in previous studies was performed on prostate cancer patient tissue specimens [88]. For these patients, the cancer of the prostate risk assessment post-surgical (CAPRA-S) score was calculated as was the Stephenson 5-year nomogram survival probability, while the GC remains the most prominent predictor of metastasis using diverse statistical probability tests [89]. These findings illustrate the application of an 
individualized and tailored approach in intermediate- and high-risk post-prostatectomy patient management with adverse histopathological patterns.

However, the promise of PCT cannot be realized if we fail to promptly identify and incorporate information from biomarkers that are predictive of therapeutic response and drug resistance into an individualized level thereby improving the interventional efficacy and preventing emergence of cancer resistance. This way, clinicians can avoid applying adjuvant therapies to patients at low risk of recurrence and stop administrating with inefficient agents. To date there are excellent biomarkers in predicting response and benefits in clinics, as illustrated by the case of BRAF inhibitor vemurafenib which gives significantly higher response rates relative to dacarbazine, a standard care for patients with metastatic melanoma [90]. Such striking results inspired analysis of our approach to the classification and treatment of malignancies in an age of molecular markers and targeted therapy [91].

Despite the exciting progress in establishing such "fine tuning" approaches, there are numerous challenges ahead to overcome before successful implementation of PCT in clinical oncology. Given the biological complexity and dynamic properties of the TME, technical obstacles such as limitations of molecular assays, lack of appropriate pharmaceuticals and shortcomings of reimbursement mechanisms, the "hype" surrounding PCT has yet to be adjusted with realistic methodologies [92]. Unfortunately, most of currently available treatment regimens offer prolonged survival for only a small handful of cancer patients, and how to break such a stalemate through designing innovative, tactful and precise technologies is a critical step toward 
major advances in clinical oncology.

As a previously unrecognized pathological implication of TME, the concrete traits of niches surrounding the tumor foci influence the way biomarkers for PCT are developed and utilized for cancer patients. In general, TME-specific markers for clinical detection should be established by differentiating responses between cancer cells and the TME components upon a given therapy. So far, the majority of therapy-oriented biomarkers adapted for PCT are present in subtypes of distinct cancers, and involve activated oncogenes targetable by small molecule inhibitors such as anaplastic lymphoma kinase (ALK) or EGFR mutations in lung carcinomas and human epidermal growth factor receptor-2 (HER2) or BRCA1/2 overexpression in breast tumors, or by monoclonal antibodies such as KRAS in colorectal cancers and BRAF in melanomas [63, 93-95]. Indeed, a substantial percentage of these patients do not respond to mainstream treatments, and high resolution genomic assays failed to interpret the discordance, inferring significant TME implication in reducing therapeutic efficacy in clinics.

\section{Significance of preclinical studies in promoting PCT advancements}

In contrast to clinical investigation, preclinical models can effectively incorporate tumor-stroma interactions and help identify candidate markers for medical validation. Although it is unlikely for the experimental data from preclinical studies to perfectly recapitulate clinical conditions, the resulting improvement can prominently fill the gap between benchside findings and bedside etiology.

For decades cell lines represent a powerful tool for cancer research, as they 
facilitate studies of genetic drivers or suppressors of human malignancies and multiple markers associated with response to therapeutics, as supported by the systematic translation from cancer cell line encyclopedia (CCLE) [96, 97]. Further, since primary cancer cells without long term exposure to ex vivo conditions remain higher TME-dependence than established cell lines, it is reasonable to expand the research of patient-derived cancer cells by in vitro co-culture assays and/or orthotopic animal models [98]. In contrast to conventional two-dimensional (2D) culture, the 3D organoid system that integrates updated technologies into new tissue models for biomarker discovery offers valuable opportunities to identify novel drug targets and predict patient responses to anticancer treatments [99]. Furthermore, data contributed by orthotopic studies involving patient samples from distinct pathological phases help disclose specific tumor-microenvironment interaction patterns, a subdiscipline of cancer biology that received significant attention in recent years particular those engaging humanized mouse models.

Despite the genomic difference between human and mouse, sufficient overlapping properties provide unique opportunities to generate informative clues across multiple pathophysiological barriers. Taking advantage of such similarity, humanized mouse models are being developed, which can effectively reconstitute malignancies with intact immunity in mice carrying tumors of human origin. For instance, simultaneous implantation of human peripheral blood lymphocytes (PBL), DC and prostate tumors to NOD/SCID/IL-2R $\gamma$ null (NSG) mice builds in a huPBL-NSG model that recapitulates the human tumor infiltrating lymphocyte (TIL) 
development and allows evaluation of tumor and immune system interaction, which can be performed in neither human patients nor regular mice [100]. More importantly, the capacity to manipulate special TME cell lineages or functional components permits hypothesis examination and outcome assessment in a humanized system that is more relevant than conventional mouse models, including the first generation of patient-derived xenografts (PDFs). Following such an exemplary concept, human hematopoietic stem and progenitor cells (HSPCs) are expanded to reconstitute the radiation-depleted bone marrow of a NSG mouse which received a patient's tumor, generating a "XactMice" [101]. Immune and stromal cells of human origin propagated in these animals help recapitulate the TME of an implanted xenograft, circumvent any potential genetic drift and provide an optimal tumor model to guide patient treatment, significantly accelerating PCT studies.

Novel animal models that simulate tumor progression in a clinically relevant TME represent a cornerstone for development of anticancer pharmacology. The design, discovery and exploitation of chemotherapeutic and targeted agents require further understanding the pathological roles of the TME. Furthermore, prospective outputs from continued PCT studies will allow tailoring of therapies on a patient-to-patient mode, a process not determined by cancer cells exclusively but rather through combining tumor features and TME biomarkers, the latter experimentally probed with high-throughput techniques. Treatment response evaluated by such orthogonal approaches holds significant promise as the next frontier that leads the translational medicine and empowers innovation of clinical 
oncology.

\section{Concluding remarks and future avenues}

Next generation sequencing (NGS) enables genome-wide personalized oncology efforts with the specialty and infrastructure necessary for identification and prioritization of tumor genome variants, as piloted by the oncomine comprehensive panel (OCP) which represents a streamlined and broadly applicable targeted NGS system to advance precision oncology [102]. In contrast, biological mechanisms of resistance to conventional cytotoxic chemotherapeutics and targeted therapies designed for specific molecules share multiple features, including activated prosurvival pathways and disabled apoptotic machineries, together constituting response variation that awaits precise treatments [103]. For instance, metastatic castration-resistant prostate cancer (mCRPC) is usually incurable and represents an area of substantial unmet medical need, and multiple systems such as the RANKL/RANK/OPG, IGF-I, FGF and Wnt/DKK-1 pathways are targetable for suppression of tumor growth and therapeutic resistance [104]. Pathological roles of the TME in modulating tumor sensitivity is being increasingly recognized as a key aspect for development of modern anticancer therapeutics. It is well accepted that tumor-stroma interplay dictates cell signaling, metabolism, survival, proliferation and therapeutic response. Resistance or sensitization of malignancies to certain pharmacological agents depend not only on intrinsic traits of cancer cells, but substantially on the context of a specific TME. Given the mounting arsenal of anticancer agents, improving preclinical models and the advent of state-of-the-art 
screening technologies, unprecedented opportunities are available to monitor and overcome drug resistance. For example, through clinical assessment of predictive biomarkers to enable patient stratification according to the TME status which images distinct TME responses particularly upon exposure of cancer patients to genotoxic chemotherapies, rational therapeutic combinations can be considered to minimize the impact of an activated TME on disease exacerbation (Figure 2) [105, 106]. Further, advances in in vitro screening platforms and in vivo orthotopic xenograft mouse models allow comprehensive characterization of the implication of the TME in modifying therapeutic efficacy. It is no doubt that recent advances will ideally bridge the gap between preclinical studies and clinical trials of anticancer regimens.

The clinical goal of PCT is to target aberrations that drive tumor growth and survival, by administering the appropriate drug combination for each individual patient. This is becoming increasingly achievable with rapid progress in cutting edge technologies to characterize tumors and the expanding repertoire of therapeutic agents that target TME constituents. However, there remain numerous challenges to take and barriers to surpass before we are able to conquer the diseases on the promise of PCT. In the current era of precision medicine, partnerships between academia and industry as well as significant philanthropic support is essential to facilitate comprehensive molecular characterization to demonstrate that it benefits patients [92]. However, ultimately PCT will become the both clinically preferred and financially available model, by treating a cancer patient with the right therapy, at the first time, generating best responses and providing medical cures. 


\section{Acknowledgements}

The author sincerely apologizes for not being able to thoroughly cite the contribution of all studies related to the current topic due to space restriction, and gratefully acknowledges Drs. Peter Nelson, Judith Campisi, Stephen Plymate and their lab members for inspiring discussion and insightful comments that made the manuscript possible. This work was supported by grants from the US Department of Defense (DoD) Prostate Cancer Research Program (PCRP) (Idea Development Award PC111703), National Natural Science Foundation of China (81472709), and the National 1000 Youth Elites Research Program of China.

\section{References}

[1] D. Hanahan, R.A. Weinberg, Hallmarks of cancer: the next generation, Cell, 144 (2011) 646-674.

[2] F. Balkwill, A. Mantovani, Inflammation and cancer: back to Virchow?, Lancet, 357 (2001) 539-545.

[3] S. Paget, The distribution of secondary growths in cancer of the breast, Lancet, 133 (1889) 571-573.

[4] F. Chen, X. Zhuang, L. Lin, P. Yu, Y. Wang, Y. Shi, G. Hu, Y. Sun, New horizons in tumor microenvironment biology: challenges and opportunities, Bmc Med, 13 (2015) 278.

[5] M.R. Junttila, F.J. de Sauvage, Influence of tumour micro-environment heterogeneity on therapeutic response, Nature, 501 (2013) 346-354.

[6] Y. Sun, Translational horizons in the tumor microenvironment: harnessing breakthroughs and targeting cures, Med Res Rev, 35 (2015) 408-436.

[7] D.F. Quail, J.A. Joyce, Microenvironmental regulation of tumor progression and metastasis, Nat Med, 19 (2013) 1423-1437.

[8] T. Song, C. Dou, Y. Jia, K. Tu, X. Zheng, TIMP-1 activated carcinoma-associated fibroblasts inhibit tumor apoptosis by activating SDF1/CXCR4 signaling in hepatocellular carcinoma, Oncotarget, (2015).

[9] K. Tanaka, H. Miyata, K. Sugimura, S. Fukuda, T. Kanemura, K. Yamashita, Y. Miyazaki, T. Takahashi, Y. Kurokawa, M. Yamasaki, H. Wada, K. Nakajima, S. Takiguchi, M. Mori, Y. Doki, miR-27 is associated with chemoresistance in esophageal cancer through transformation of normal fibroblasts to cancer-associated fibroblasts, Carcinogenesis, (2015).

[10] B.C. Ozdemir, T. Pentcheva-Hoang, J.L. Carstens, X. Zheng, C.C. Wu, T.R. Simpson, H. Laklai, H. Sugimoto, C. Kahlert, S.V. Novitskiy, A. De Jesus-Acosta, P. Sharma, P. Heidari, U. Mahmood, L. Chin, H.L. Moses, V.M. Weaver, A. Maitra, J.P. Allison, V.S. LeBleu, R. Kalluri, Depletion of carcinoma-associated fibroblasts and fibrosis induces immunosuppression and accelerates pancreas cancer with reduced survival, Cancer cell, 25 (2014) 719-734.

[11] A.D. Rhim, P.E. Oberstein, D.H. Thomas, E.T. Mirek, C.F. Palermo, S.A. Sastra, E.N. Dekleva, T. 
Saunders, C.P. Becerra, I.W. Tattersa, C.B. Westphalen, J. Kitajewski, M.G. Fernandez-Barrena, M.E. Fernandez-Zapico, C. lacobuzio-Donahue, K.P. Olive, B.Z. Stanger, Stromal Elements Act to Restrain, Rather Than Support, Pancreatic Ductal Adenocarcinoma, Cancer cell, 25 (2014) 735-747.

[12] C. Duluc, S. Moatassim-Billah, M. Chalabi-Dchar, A. Perraud, R. Samain, F. Breibach, M. Gayral, P. Cordelier, M.B. Delisle, M.P. Bousquet-Dubouch, R. Tomasini, H. Schmid, M. Mathonnet, S. Pyronnet, Y. Martineau, C. Bousquet, Pharmacological targeting of the protein synthesis mTOR/4E-BP1 pathway in cancer-associated fibroblasts abrogates pancreatic tumour chemoresistance, EMBO molecular medicine, (2015).

[13] N. Erez, M. Truitt, P. Olson, S.T. Arron, D. Hanahan, Cancer-Associated Fibroblasts Are Activated in Incipient Neoplasia to Orchestrate Tumor-Promoting Inflammation in an NF-kappaB-Dependent Manner, Cancer cell, 17 (2010) 135-147.

[14] N. Erez, S. Glanz, Y. Raz, C. Avivi, I. Barshack, Cancer associated fibroblasts express pro-inflammatory factors in human breast and ovarian tumors, Biochemical and biophysical research communications, 437 (2013) 397-402.

[15] T. Nagasaki, M. Hara, H. Nakanishi, H. Takahashi, M. Sato, H. Takeyama, Interleukin-6 released by colon cancer-associated fibroblasts is critical for tumour angiogenesis: anti-interleukin- 6 receptor antibody suppressed angiogenesis and inhibited tumour-stroma interaction, British journal of cancer, 110 (2014) 469-478.

[16] X.H. Zhang, X. Jin, S. Malladi, Y. Zou, Y.H. Wen, E. Brogi, M. Smid, J.A. Foekens, J. Massague, Selection of bone metastasis seeds by mesenchymal signals in the primary tumor stroma, Cell, 154 (2013) 1060-1073.

[17] J. Yuan, M. Liu, L. Yang, G. Tu, Q. Zhu, M. Chen, H. Cheng, H. Luo, W. Fu, Z. Li, G. Yang, Acquisition of epithelial-mesenchymal transition phenotype in the tamoxifen-resistant breast cancer cell: a new role for $G$ protein-coupled estrogen receptor in mediating tamoxifen resistance through cancer-associated fibroblast-derived fibronectin and beta1-integrin signaling pathway in tumor cells, Breast Cancer Res, 17 (2015) 69.

[18] M. Peiris-Pages, F. Sotgia, M.P. Lisanti, Chemotherapy induces the cancer-associated fibroblast phenotype, activating paracrine Hedgehog-GLI signalling in breast cancer cells, Oncotarget, 6 (2015) 10728-10745.

[19] S.M. Weis, D.A. Cheresh, Tumor angiogenesis: molecular pathways and therapeutic targets, Nat Med, 17 (2011) 1359-1370.

[20] G.L. Semenza, Cancer-stromal cell interactions mediated by hypoxia-inducible factors promote angiogenesis, lymphangiogenesis, and metastasis, Oncogene, 32 (2013) 4057-4063.

[21] O. Tredan, C.M. Galmarini, K. Patel, I.F. Tannock, Drug resistance and the solid tumor microenvironment, J. Natl. Cancer Inst., 99 (2007) 1441-1454.

[22] M.M. Yuan, Y.Y. Xu, L. Chen, X.Y. Li, J. Qin, Y. Shen, TLR3 expression correlates with apoptosis, proliferation and angiogenesis in hepatocellular carcinoma and predicts prognosis, BMC cancer, 15 (2015) 245.

[23] C. Ariotti, V.P. Wagner, G. Salvadori, V.C. Carrard, M.A. Martins, J.J. Filho, L. Meurer, M.D. Martins, VEGFR1 and VEGFR2 in lip carcinogenesis and its association with microvessel density, Tumour biology : the journal of the International Society for Oncodevelopmental Biology and Medicine, (2015).

[24] J.G. Lee, R. Wu, Erlotinib-Cisplatin Combination Inhibits Growth and Angiogenesis through c-MYC and HIF-1 alpha in EGFR-Mutated Lung Cancer In Vitro and In Vivo, Neoplasia, 17 (2015) 190-200.

[25] P.S. Hegde, A.M. Jubb, D. Chen, N.F. Li, Y.G. Meng, C. Bernaards, R. Elliott, S.J. Scherer, D.S. Chen, 
Predictive impact of circulating vascular endothelial growth factor in four phase III trials evaluating bevacizumab, Clinical cancer research : an official journal of the American Association for Cancer Research, 19 (2013) 929-937.

[26] K. Yamada, N. Maishi, K. Akiyama, A.M. Towfik, N. Ohga, T. Kawamoto, M. Shindoh, N. Takahashi, T. Kamiyama, Y. Hida, A. Taketomi, K. Hida, CXCL12-CXCR7 axis is important for tumor endothelial cell angiogenic property, Int J Cancer, [Epub ahead of print] (2015).

[27] K.T. Flaherty, J.B. Manola, M. Pins, D.F. McDermott, M.B. Atkins, J.J. Dutcher, D.J. George, K.A. Margolin, R.S. DiPaola, BEST: A Randomized Phase II Study of Vascular Endothelial Growth Factor, RAF Kinase, and Mammalian Target of Rapamycin Combination Targeted Therapy With Bevacizumab, Sorafenib, and Temsirolimus in Advanced Renal Cell Carcinoma-A Trial of the ECOG-ACRIN Cancer Research Group (E2804), J Clin Oncol, (2015).

[28] M.M. Martino, P.S. Briquez, E. Guc, F. Tortelli, W.W. Kilarski, S. Metzger, J.J. Rice, G.A. Kuhn, R. Muller, M.A. Swartz, J.A. Hubbell, Growth Factors Engineered for Super-Affinity to the Extracellular Matrix Enhance Tissue Healing, Science, 343 (2014) 885-888.

[29] F. Klemm, J.A. Joyce, Microenvironmental regulation of therapeutic response in cancer, Trends in cell biology, 25 (2015) 198-213.

[30] P. Friedl, S. Alexander, Cancer Invasion and the Microenvironment: Plasticity and Reciprocity, Cell, 147 (2011) 992-1009.

[31] V.M. Weaver, S. Lelievre, J.N. Lakins, M.A. Chrenek, J.C. Jones, F. Giancotti, Z. Werb, M.J. Bissell, beta4 integrin-dependent formation of polarized three-dimensional architecture confers resistance to apoptosis in normal and malignant mammary epithelium, Cancer cell, 2 (2002) 205-216.

[32] H.L. Goel, A. Sayeed, M. Breen, M.J. Zarif, D.S. Garlick, I. Leav, R.J. Davis, T.J. Fitzgerald, A. Morrione, C.C. Hsieh, Q. Liu, A.P. Dicker, D.C. Altieri, L.R. Languino, beta1 integrins mediate resistance to ionizing radiation in vivo by inhibiting C-Jun amino terminal kinase 1, J Cell Physiol, 228 (2013) 1601-1609.

[33] L. Seguin, S. Kato, A. Franovic, M.F. Camargo, J. Lesperance, K.C. Elliott, M. Yebra, A. Mielgo, A.M. Lowy, H. Husain, T. Cascone, L.X. Diao, J. Wang, I.I. Wistuba, J.V. Heymach, S.M. Lippman, J.S. Desgrosellier, S. Anand, S.M. Weis, D.A. Cheresh, An integrin beta(3)-KRAS-RalB complex drives tumour stemness and resistance to EGFR inhibition, Nat Cell Biol, 16 (2014) 457-U172.

[34] K.R. Levental, H.M. Yu, L. Kass, J.N. Lakins, M. Egeblad, J.T. Erler, S.F.T. Fong, K. Csiszar, A. Giaccia, W. Weninger, M. Yamauchi, D.L. Gasser, V.M. Weaver, Matrix Crosslinking Forces Tumor Progression by Enhancing Integrin Signaling, Cell, 139 (2009) 891-906.

[35] K.P. Olive, M.A. Jacobetz, C.J. Davidson, A. Gopinathan, D. McIntyre, D. Honess, B. Madhu, M.A. Goldgraben, M.E. Caldwell, D. Allard, K.K. Frese, G. Denicola, C. Feig, C. Combs, S.P. Winter, H. Ireland-Zecchini, S. Reichelt, W.J. Howat, A. Chang, M. Dhara, L. Wang, F. Ruckert, R. Grutzmann, C. Pilarsky, K. Izeradjene, S.R. Hingorani, P. Huang, S.E. Davies, W. Plunkett, M. Egorin, R.H. Hruban, N. Whitebread, K. McGovern, J. Adams, C. Iacobuzio-Donahue, J. Griffiths, D.A. Tuveson, Inhibition of Hedgehog signaling enhances delivery of chemotherapy in a mouse model of pancreatic cancer, Science, 324 (2009) 1457-1461.

[36] A. Bergamaschi, E. Tagliabue, T. Sorlie, B. Naurne, T. Triulzi, R. Orlandi, H.G. Russnes, J.M. Nesland, R. Tammi, P. Auvinen, V.M. Kosma, S. Menard, A.L. Borresen-Dale, Extracellular matrix signature identifies breast cancer subgroups with different clinical outcome, Journal of Pathology, 214 (2008) 357-367.

[37] A. Naba, K.R. Clauser, S. Hoersch, H. Liu, S.A. Carr, R.O. Hynes, The matrisome: in silico definition 
and in vivo characterization by proteomics of normal and tumor extracellular matrices, Molecular \& cellular proteomics : MCP, 11 (2012) M111 014647.

[38] L.R. Gomes, A.T. Vessoni, C.F. Menck, Three-dimensional microenvironment confers enhanced sensitivity to doxorubicin by reducing p53-dependent induction of autophagy, Oncogene, (2015).

[39] M.X. Feng, M.Z. Ma, Y. Fu, J. Li, T. Wang, F. Xue, J.J. Zhang, W.X. Qin, J.R. Gu, Z.G. Zhang, Q. Xia, Elevated autocrine EDIL3 protects hepatocellular carcinoma from anoikis through RGD-mediated integrin activation, Mol Cancer, 13 (2014).

[40] D.M. Pardoll, The blockade of immune checkpoints in cancer immunotherapy, Nature reviews. Cancer, 12 (2012) 252-264.

[41] F. Shojaei, X. Wu, X. Qu, M. Kowanetz, L. Yu, M. Tan, Y.G. Meng, N. Ferrara, G-CSF-initiated myeloid cell mobilization and angiogenesis mediate tumor refractoriness to anti-VEGF therapy in mouse models, Proceedings of the National Academy of Sciences of the United States of America, 106 (2009) 6742-6747.

[42] L.J. Bayne, G.L. Beatty, N. Jhala, C.E. Clark, A.D. Rhim, B.Z. Stanger, R.H. Vonderheide, Tumor-derived granulocyte-macrophage colony-stimulating factor regulates myeloid inflammation and T cell immunity in pancreatic cancer, Cancer cell, 21 (2012) 822-835.

[43] G.T. Motz, G. Coukos, The parallel lives of angiogenesis and immunosuppression: cancer and other tales, Nature reviews. Immunology, 11 (2011) 702-711.

[44] Y. Komohara, T. Morita, D.A. Annan, H. Horlad, K. Ohnishi, S. Yamada, T. Nakayama, S. Kitada, S. Suzu, I. Kinoshita, H. Dosaka-Akita, K. Akashi, M. Takeya, M. Jinushi, The coordinated actions of TIM-3 on cancer and myeloid cells in the regulation of tumorigenicity and clinical prognosis in clear cell renal cell carcinomas, Cancer immunology research, (2015).

[45] G. Finak, N. Bertos, F. Pepin, S. Sadekova, M. Souleimanova, H. Zhao, H. Chen, G. Omeroglu, S. Meterissian, A. Omeroglu, M. Hallett, M. Park, Stromal gene expression predicts clinical outcome in breast cancer, Nat Med, 14 (2008) 518-527.

[46] N. Weizman, Y. Krelin, A. Shabtay-Orbach, M. Amit, Y. Binenbaum, R.J. Wong, Z. Gil, Macrophages mediate gemcitabine resistance of pancreatic adenocarcinoma by upregulating cytidine deaminase, Oncogene, 33 (2014) 3812-3819.

[47] C. Yang, L. He, P. He, Y. Liu, W. Wang, Y. He, Y. Du, F. Gao, Increased drug resistance in breast cancer by tumor-associated macrophages through IL-10/STAT3/bcl-2 signaling pathway, Medical oncology, 32 (2015) 352.

[48] S. Wan, E. Zhao, I. Kryczek, L. Vatan, A. Sadovskaya, G. Ludema, D.M. Simeone, W. Zou, T.H. Welling, Tumor-associated macrophages produce interleukin 6 and signal via STAT3 to promote expansion of human hepatocellular carcinoma stem cells, Gastroenterology, 147 (2014) 1393-1404.

[49] B. Ruffell, L.M. Coussens, Macrophages and Therapeutic Resistance in Cancer, Cancer cell, 27 (2015) 462-472.

[50] F. Hossain, A.A. Al-Khami, D. Wyczechowska, C. Hernandez, L. Zheng, K. Reiss, L. Del Valle, J. Trillo-Tinoco, T. Maj, W. Zou, P.C. Rodriguez, A.C. Ochoa, Inhibition of Fatty Acid Oxidation Modulates Immunosuppressive Functions of Myeloid-Derived Suppressor Cells and Enhances Cancer Therapies, Cancer immunology research, (2015).

[51] M. Simons, G. Raposo, Exosomes - vesicular carriers for intercellular communication, Current opinion in cell biology, 21 (2009) 575-581.

[52] J. Schageman, E. Zeringer, M. Li, T. Barta, K. Lea, J. Gu, S. Magdaleno, R. Setterquist, A.V. Vlassov, The complete exosome workflow solution: from isolation to characterization of RNA cargo, BioMed 
research international, 2013 (2013) 253957.

[53] H. Peinado, M. Aleckovic, S. Lavotshkin, I. Matei, B. Costa-Silva, G. Moreno-Bueno, M. Hergueta-Redondo, C. Williams, G. Garcia-Santos, C.M. Ghajar, A. Nitadori-Hoshino, C. Hoffman, K. Badal, B.A. Garcia, M.K. Callahan, J.D. Yuan, V.R. Martins, J. Skog, R.N. Kaplan, M.S. Brady, J.D. Wolchok, P.B. Chapman, Y.B. Kang, J. Bromberg, D. Lyden, Melanoma exosomes educate bone marrow progenitor cells toward a pro-metastatic phenotype through MET, Nat Med, 18 (2012) 883-+.

[54] T. Aung, B. Chapuy, D. Vogel, D. Wenzel, M. Oppermann, M. Lahmann, T. Weinhage, K. Menck, T. Hupfeld, R. Koch, L. Trumper, G.G. Wulf, Exosomal evasion of humoral immunotherapy in aggressive B-cell lymphoma modulated by ATP-binding cassette transporter A3, Proceedings of the National Academy of Sciences of the United States of America, 108 (2011) 15336-15341.

[55] V. Ciravolo, V. Huber, G.C. Ghedini, E. Venturelli, F. Bianchi, M. Campiglio, D. Morelli, A. Villa, P. Della Mina, S. Menard, P. Filipazzi, L. Rivoltini, E. Tagliabue, S.M. Pupa, Potential role of HER2-overexpressing exosomes in countering trastuzumab-based therapy, J Cell Physiol, 227 (2012) 658-667.

[56] V. Luga, L. Zhang, A.M. Viloria-Petit, A.A. Ogunjimi, M.R. Inanlou, E. Chiu, M. Buchanan, A.N. Hosein, M. Basik, J.L. Wrana, Exosomes mediate stromal mobilization of autocrine Wnt-PCP signaling in breast cancer cell migration, Cell, 151 (2012) 1542-1556.

[57] M.C. Boelens, T.J. Wu, B.Y. Nabet, B. Xu, Y. Qiu, T. Yoon, D.J. Azzam, C. Twyman-Saint Victor, B.Z. Wiemann, H. Ishwaran, P.J. Ter Brugge, J. Jonkers, J. Slingerland, A.J. Minn, Exosome transfer from stromal to breast cancer cells regulates therapy resistance pathways, Cell, 159 (2014) 499-513.

[58] L. Lugini, S. Cecchetti, V. Huber, F. Luciani, G. Macchia, F. Spadaro, L. Paris, L. Abalsamo, M. Colone, A. Molinari, F. Podo, L. Rivoltini, C. Ramoni, S. Fais, Immune surveillance properties of human NK cell-derived exosomes, J Immunol, 189 (2012) 2833-2842.

[59] T. Naslund, U. Gehrmann, K. Qazi, M. Karlsson, S. Gabrielsson, Dendritic cell derived exosomes need to activate both T and B cells to induce antitumor immunity, J Immunol, 190 (2013).

[60] K.B. Challagundla, P.M. Wise, P. Neviani, H. Chava, M. Murtadha, T. Xu, R. Kennedy, C. Ivan, X. Zhang, I. Vannini, F. Fanini, D. Amadori, G.A. Calin, M. Hadjidaniel, H. Shimada, A. Jong, R.C. Seeger, S. Asgharzadeh, A. Goldkorn, M. Fabbri, Exosome-Mediated Transfer of microRNAs Within the Tumor Microenvironment and Neuroblastoma Resistance to Chemotherapy, J Natl Cancer Inst, 107 (2015).

[61] C. Corcoran, S. Rani, L. O'Driscoll, miR-34a is an Intracellular and Exosomal Predictive Biomarker for Response to Docetaxel with Clinical Relevance to Prostate Cancer Progression, The Prostate, 74 (2014) 1320-1334.

[62] R.U. Takahashi, H. Miyazaki, T. Ochiya, The Roles of MicroRNAs in Breast Cancer, Cancers, 7 (2015) 598-616.

[63] A.C. Obenauf, Y. Zou, A.L. Ji, S. Vanharanta, W. Shu, H. Shi, X. Kong, M.C. Bosenberg, T. Wiesner, N. Rosen, R.S. Lo, J. Massague, Therapy-induced tumour secretomes promote resistance and tumour progression, Nature, 520 (2015) 368-372.

[64] B.A. Chabner, T.G. Roberts, Jr., Timeline: Chemotherapy and the war on cancer, Nature reviews. Cancer, 5 (2005) 65-72.

[65] Y. Sun, P.S. Nelson, Molecular pathways: involving microenvironment damage responses in cancer therapy resistance, Clinical cancer research : an official journal of the American Association for Cancer Research, 18 (2012) 4019-4025.

[66] J.P. Coppe, C.K. Patil, F. Rodier, Y. Sun, D.P. Munoz, J. Goldstein, P.S. Nelson, P.Y. Desprez, J. Campisi, Senescence-associated secretory phenotypes reveal cell-nonautonomous functions of oncogenic RAS 
and the p53 tumor suppressor, PLoS biology, 6 (2008) 2853-2868.

[67] T. Kuilman, D.S. Peeper, Senescence-messaging secretome: SMS-ing cellular stress, Nature reviews. Cancer, 9 (2009) 81-94.

[68] J. Neves, M. Demaria, J. Campisi, H. Jasper, Of Flies, Mice, and Men: Evolutionarily Conserved Tissue Damage Responses and Aging, Developmental cell, 32 (2015) 9-18.

[69] T. Kuilman, C. Michaloglou, L.C. Vredeveld, S. Douma, R. van Doorn, C.J. Desmet, L.A. Aarden, W.J. Mooi, D.S. Peeper, Oncogene-induced senescence relayed by an interleukin-dependent inflammatory network, Cell, 133 (2008) 1019-1031.

[70] J.C. Acosta, A. O'Loghlen, A. Banito, M.V. Guijarro, A. Augert, S. Raguz, M. Fumagalli, M. Da Costa, C. Brown, N. Popov, Y. Takatsu, J. Melamed, F. d'Adda di Fagagna, D. Bernard, E. Hernando, J. Gil, Chemokine signaling via the CXCR2 receptor reinforces senescence, Cell, 133 (2008) 1006-1018.

[71] F. Rodier, J.P. Coppe, C.K. Patil, W.A. Hoeijmakers, D.P. Munoz, S.R. Raza, A. Freund, E. Campeau, A.R. Davalos, J. Campisi, Persistent DNA damage signalling triggers senescence-associated inflammatory cytokine secretion, Nat Cell Biol, 11 (2009) 973-979.

[72] F. Rodier, D.P. Munoz, R. Teachenor, V. Chu, O. Le, D. Bhaumik, J.P. Coppe, E. Campeau, C.M. Beausejour, S.H. Kim, A.R. Davalos, J. Campisi, DNA-SCARS: distinct nuclear structures that sustain damage-induced senescence growth arrest and inflammatory cytokine secretion, J Cell Sci, 124 (2011) 68-81.

[73] Y. Sun, J. Campisi, C. Higano, T.M. Beer, P. Porter, I. Coleman, L. True, P.S. Nelson, Treatment-induced damage to the tumor microenvironment promotes prostate cancer therapy resistance through WNT16B, Nat Med, 18 (2012) 1359-1368.

[74] L.A. Gilbert, M.T. Hemann, DNA damage-mediated induction of a chemoresistant niche, Cell, 143 (2010) 355-366.

[75] L.A. Gilbert, M.T. Hemann, Chemotherapeutic resistance: surviving stressful situations, Cancer Res, 71 (2011) 5062-5066.

[76] J.M.L. Roodhart, L.G.M. Daenen, E.C.A. Stigter, H.J. Prins, J. Gerrits, J.M. Houthuijzen, M.G. Gerritsen, H.S. Schipper, M.J.G. Backer, M. van Amersfoort, J.S.P. Vermaat, P. Moerer, K. Ishihara, E. Kalkhoven, J.H. Beijnen, P.W.B. Derksen, R.H. Medema, A.C. Martens, A.B. Brenkman, E.E. Voest, Mesenchymal Stem Cells Induce Resistance to Chemotherapy through the Release of Platinum-Induced Fatty Acids, Cancer cell, 20 (2011) 370-383.

[77] Y. Shaked, E. Henke, J.M.L. Roodhart, P. Mancuso, M.H.G. Langenberg, M. Colleoni, L.G. Daenen, S. Man, P. Xu, U. Emmenegger, T. Tang, Z.P. Zhu, L. Witte, R.M. Strieter, F. Bertolini, E.E. Voest, R. Benezra, R.S. Kerbell, Rapid chemotherapy-induced acute endothelial progenitor cell mobilization: Implications for antiangiogenic drugs as chemosensitizing agents, Cancer cell, 14 (2008) 263-273.

[78] C.W. Duan, J. Shi, J. Chen, B. Wang, Y.H. Yu, X. Qin, X.C. Zhou, Y.J. Cai, Z.Q. Li, F. Zhang, M.Z. Yin, Y. Tao, J.Q. Mi, L.H. Li, T. Enver, G.Q. Chen, D.L. Hong, Leukemia propagating cells rebuild an evolving niche in response to therapy, Cancer cell, 25 (2014) 778-793.

[79] M. Kim, Y.J. Koh, K.E. Kim, B.I. Koh, D.H. Nam, K. Alitalo, I. Kim, G.Y. Koh, CXCR4 signaling regulates metastasis of chemoresistant melanoma cells by a lymphatic metastatic niche, Cancer Res, 70 (2010) 10411-10421.

[80] M. Mannino, A.J. Chalmers, Radioresistance of glioma stem cells: intrinsic characteristic or property of the 'microenvironment-stem cell unit'?, Molecular oncology, 5 (2011) 374-386.

[81] E. Zoni, G. van der Pluijm, P.C. Gray, M. Kruithof-de Julio, Epithelial Plasticity in Cancer: Unmasking a MicroRNA Network for TGF-beta-, Notch-, and Wnt-Mediated EMT, J Oncol, 2015 (2015) 198967. 
[82] B.G. Cuiffo, A. Campagne, G.W. Bell, A. Lembo, F. Orso, E.C. Lien, M.K. Bhasin, M. Raimo, S.E. Hanson, A. Marusyk, D. El-Ashry, P. Hematti, K. Polyak, F. Mechta-Grigoriou, O. Mariani, S. Volinia, A. Vincent-Salomon, D. Taverna, A.E. Karnoub, MSC-regulated microRNAs converge on the transcription factor FOXP2 and promote breast cancer metastasis, Cell Stem Cell, 15 (2014) 762-774.

[83] J. Landsberg, J. Kohlmeyer, M. Renn, T. Bald, M. Rogava, M. Cron, M. Fatho, V. Lennerz, T. Wolfel, M. Holzel, T. Tuting, Melanomas resist T-cell therapy through inflammation-induced reversible dedifferentiation, Nature, 490 (2012) 412-416.

[84] K.P. Bhat, V. Balasubramaniyan, B. Vaillant, R. Ezhilarasan, K. Hummelink, F. Hollingsworth, K. Wani, L. Heathcock, J.D. James, L.D. Goodman, S. Conroy, L. Long, N. Lelic, S. Wang, J. Gumin, D. Raj, Y. Kodama, A. Raghunathan, A. Olar, K. Joshi, C.E. Pelloski, A. Heimberger, S.H. Kim, D.P. Cahill, G. Rao, W.F. Den Dunnen, H.W. Boddeke, H.S. Phillips, I. Nakano, F.F. Lang, H. Colman, E.P. Sulman, K. Aldape, Mesenchymal differentiation mediated by NF-kappaB promotes radiation resistance in glioblastoma, Cancer cell, 24 (2013) 331-346.

[85] E.M. Dijkgraaf, M. Heusinkveld, B. Tummers, L.T. Vogelpoel, R. Goedemans, V. Jha, J.W. Nortier, M.J. Welters, J.R. Kroep, S.H. van der Burg, Chemotherapy alters monocyte differentiation to favor generation of cancer-supporting M2 macrophages in the tumor microenvironment, Cancer Res, 73 (2013) 2480-2492.

[86] F. Klug, H. Prakash, P.E. Huber, T. Seibel, N. Bender, N. Halama, C. Pfirschke, R.H. Voss, C. Timke, L. Umansky, K. Klapproth, K. Schakel, N. Garbi, D. Jager, J. Weitz, H. Schmitz-Winnenthal, G.J. Hammerling, P. Beckhove, Low-dose irradiation programs macrophage differentiation to an iNOS(+)/M1 phenotype that orchestrates effective T cell immunotherapy, Cancer cell, 24 (2013) 589-602.

[87] C. Tripathi, B.N. Tewari, R.K. Kanchan, K.S. Baghel, N. Nautiyal, R. Shrivastava, H. Kaur, M.L. Bhatt, S. Bhadauria, Macrophages are recruited to hypoxic tumor areas and acquire a pro-angiogenic M2-polarized phenotype via hypoxic cancer cell derived cytokines Oncostatin $M$ and Eotaxin, Oncotarget, 5 (2014) 5350-5368.

[88] R.B. Den, K. Yousefi, E.J. Trabulsi, F. Abdollah, V. Choeurng, F.Y. Feng, A.P. Dicker, C.D. Lallas, L.G. Gomella, E. Davicioni, R.J. Karnes, Genomic classifier identifies men with adverse pathology after radical prostatectomy who benefit from adjuvant radiation therapy, J Clin Oncol, 33 (2015) 944-951.

[89] J.P. Sedelaar, J.A. Schalken, The need for a personalized approach for prostate cancer management, Bmc Med, 13 (2015) 109.

[90] P.B. Chapman, A. Hauschild, C. Robert, J.B. Haanen, P. Ascierto, J. Larkin, R. Dummer, C. Garbe, A. Testori, M. Maio, D. Hogg, P. Lorigan, C. Lebbe, T. Jouary, D. Schadendorf, A. Ribas, S.J. O'Day, J.A. Sosman, J.M. Kirkwood, A.M. Eggermont, B. Dreno, K. Nolop, J. Li, B. Nelson, J. Hou, R.J. Lee, K.T. Flaherty, G.A. McArthur, B.-S. Group, Improved survival with vemurafenib in melanoma with BRAF V600E mutation, The New England journal of medicine, 364 (2011) 2507-2516.

[91] K. Young, A. Minchom, J. Larkin, BRIM-1, -2 and -3 trials: improved survival with vemurafenib in metastatic melanoma patients with a BRAF(V600E) mutation, Future oncology, 8 (2012) 499-507.

[92] F. Meric-Bernstam, G.B. Mills, Overcoming implementation challenges of personalized cancer therapy, Nature reviews. Clinical oncology, 9 (2012) 542-548.

[93] P. Saintigny, J.A. Burger, Recent advances in non-small cell lung cancer biology and clinical management, Discovery medicine, 13 (2012) 287-297.

[94] G. Curigliano, New drugs for breast cancer subtypes: targeting driver pathways to overcome resistance, Cancer Treat Rev, 38 (2012) 303-310. 
[95] E. Van Cutsem, H.J. Lenz, C.H. Kohne, V. Heinemann, S. Tejpar, I. Melezinek, F. Beier, C. Stroh, P. Rougier, J.H. van Krieken, F. Ciardiello, Fluorouracil, leucovorin, and irinotecan plus cetuximab treatment and RAS mutations in colorectal cancer, J Clin Oncol, 33 (2015) 692-700.

[96] D. Sonkin, M. Hassan, D.J. Murphy, T.V. Tatarinova, Tumor suppressors status in cancer cell line Encyclopedia, Molecular oncology, 7 (2013) 791-798.

[97] J. Barretina, G. Caponigro, N. Stransky, K. Venkatesan, A.A. Margolin, S. Kim, C.J. Wilson, J. Lehar, G.V. Kryukov, D. Sonkin, A. Reddy, M. Liu, L. Murray, M.F. Berger, J.E. Monahan, P. Morais, J. Meltzer, A. Korejwa, J. Jane-Valbuena, F.A. Mapa, J. Thibault, E. Bric-Furlong, P. Raman, A. Shipway, I.H. Engels, J. Cheng, G.K. Yu, J. Yu, P. Aspesi, Jr., M. de Silva, K. Jagtap, M.D. Jones, L. Wang, C. Hatton, E. Palescandolo, S. Gupta, S. Mahan, C. Sougnez, R.C. Onofrio, T. Liefeld, L. MacConaill, W. Winckler, M. Reich, N. Li, J.P. Mesirov, S.B. Gabriel, G. Getz, K. Ardlie, V. Chan, V.E. Myer, B.L. Weber, J. Porter, M. Warmuth, P. Finan, J.L. Harris, M. Meyerson, T.R. Golub, M.P. Morrissey, W.R. Sellers, R. Schlegel, L.A. Garraway, The Cancer Cell Line Encyclopedia enables predictive modelling of anticancer drug sensitivity, Nature, 483 (2012) 603-607.

[98] D.W. McMillin, J.M. Negri, C.S. Mitsiades, The role of tumour-stromal interactions in modifying drug response: challenges and opportunities, Nature Reviews Drug Discovery, 12 (2013) 217-228.

[99] F.T. Unger, I. Witte, K.A. David, Prediction of individual response to anticancer therapy: historical and future perspectives, Cellular and molecular life sciences : CMLS, 72 (2015) 729-757.

[100] M.D. Roth, A. Harui, Human tumor infiltrating lymphocytes cooperatively regulate prostate tumor growth in a humanized mouse model, Journal for immunotherapy of cancer, 3 (2015) 12.

[101] J.J. Morton, G. Bird, S.B. Keysar, D.P. Astling, T.R. Lyons, R.T. Anderson, M.J. Glogowska, P. Estes, J.R. Eagles, P.N. Le, G. Gan, B. McGettigan, P. Fernandez, N. Padilla-Just, M. Varella-Garcia, J.I. Song, D.W. Bowles, P. Schedin, A.C. Tan, D.R. Roop, X.J. Wang, Y. Refaeli, A. Jimeno, XactMice: humanizing mouse bone marrow enables microenvironment reconstitution in a patient-derived xenograft model of head and neck cancer, Oncogene, (2015).

[102] D.H. Hovelson, A.S. McDaniel, A.K. Cani, B. Johnson, K. Rhodes, P.D. Williams, S. Bandla, G. Bien, P. Choppa, F. Hyland, R. Gottimukkala, G. Liu, M. Manivannan, J. Schageman, E. Ballesteros-Villagrana, C.S. Grasso, M.J. Quist, V. Yadati, A. Amin, J. Siddiqui, B.L. Betz, K.E. Knudsen, K.A. Cooney, F.Y. Feng, M.H. Roh, P.S. Nelson, C.J. Liu, D.G. Beer, P. Wyngaard, A.M. Chinnaiyan, S. Sadis, D.R. Rhodes, S.A. Tomlins, Development and validation of a scalable next-generation sequencing system for assessing relevant somatic variants in solid tumors, Neoplasia, 17 (2015) 385-399.

[103] C. Holohan, S. Van Schaeybroeck, D.B. Longley, P.G. Johnston, Cancer drug resistance: an evolving paradigm, Nature Reviews Cancer, 13 (2013) 714-726.

[104] P. Msaouel, J.N. Galeas, A.R. Boiles, R.R. Ruiz, M. Koutsilieris, Targeting the Bone Microenvironment in Metastatic Castration-Resistant Prostate Cancer, Curr Drug Targets, (2015).

[105] E. Alspach, K.C. Flanagan, X. Luo, M.K. Ruhland, H. Huang, E. Pazolli, M.J. Donlin, T. Marsh, D. Piwnica-Worms, J. Monahan, D.V. Novack, S.S. McAllister, S.A. Stewart, p38MAPK plays a crucial role in stromal-mediated tumorigenesis, Cancer discovery, 4 (2014) 716-729.

[106] R.M. Laberge, Y. Sun, A.V. Orjalo, C.K. Patil, A. Freund, L. Zhou, S.C. Curran, A.R. Davalos, K.A. Wilson-Edell, S. Liu, C. Limbad, M. Demaria, P. Li, G.B. Hubbard, Y. Ikeno, M. Javors, P.Y. Desprez, C.C. Benz, P. Kapahi, P.S. Nelson, J. Campisi, MTOR regulates the pro-tumorigenic senescence-associated secretory phenotype by promoting IL1A translation, Nat Cell Biol, (2015). 


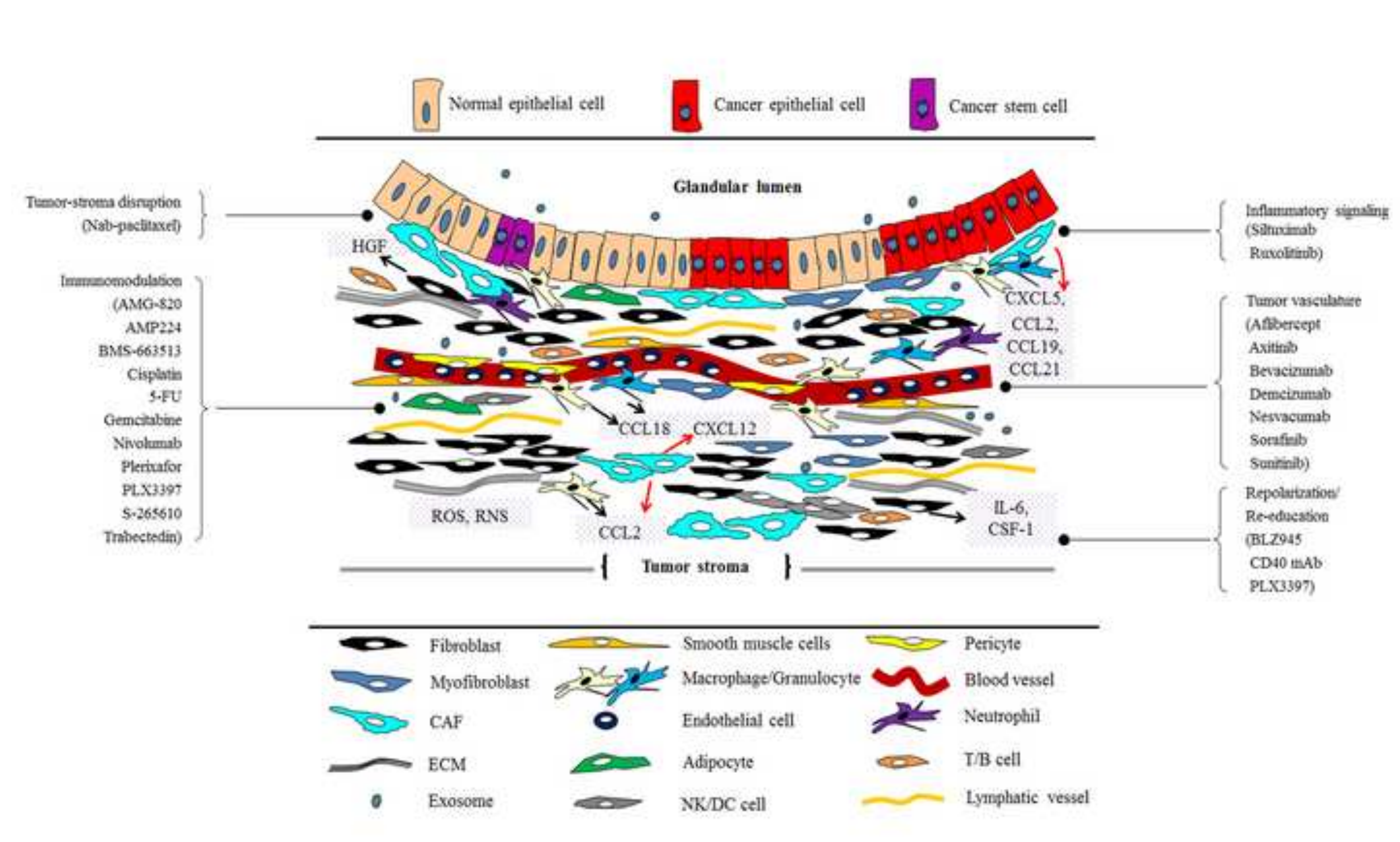

.

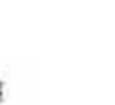

.




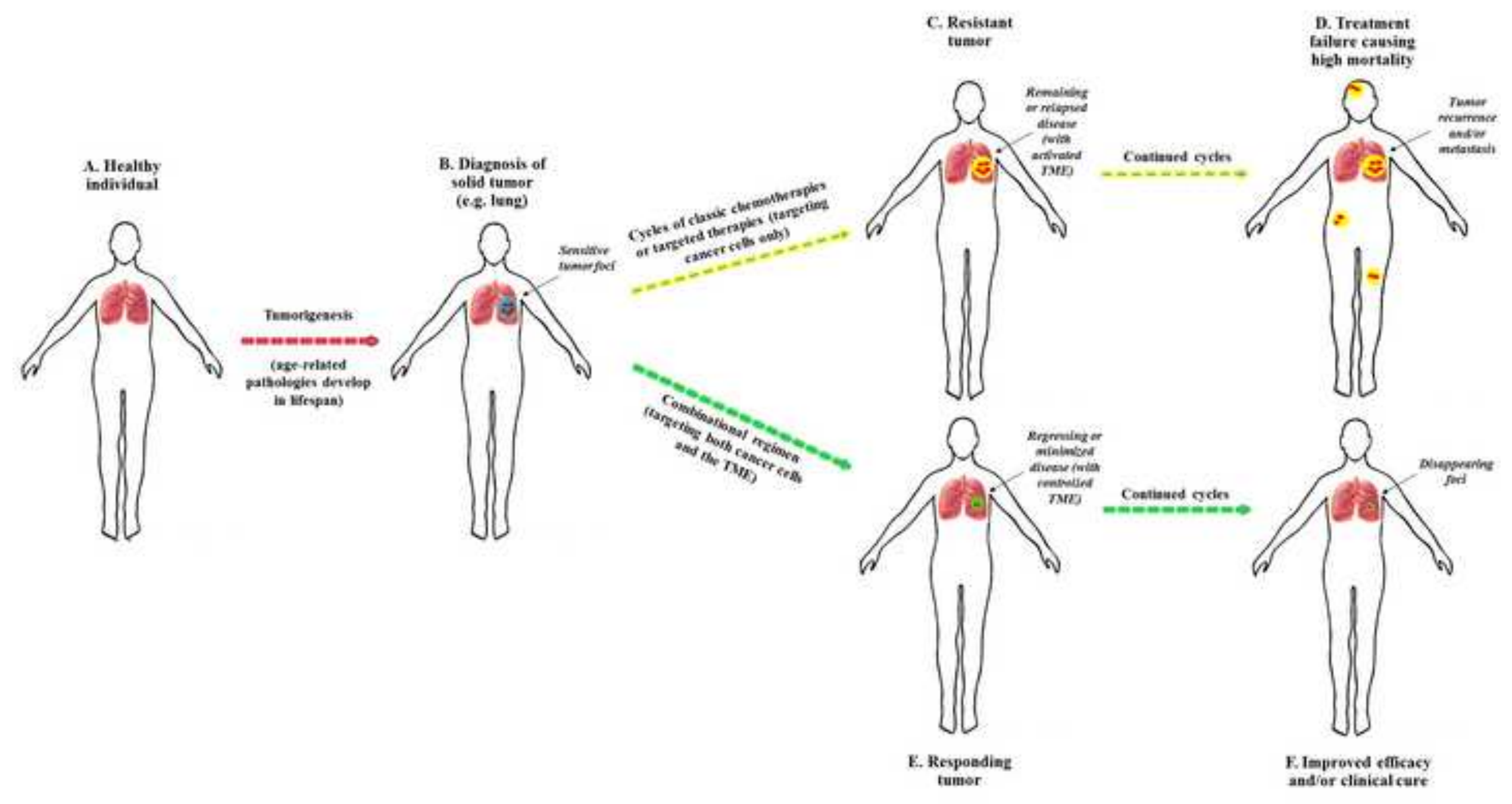


Table 1. A representative group of therapeutic agents that target specific compartments of the TME, a critical pathological etiology that calls for attention in precision oncology.

\begin{tabular}{|c|c|c|c|c|}
\hline Molecule & Target & $\begin{array}{l}\text { Molecular } \\
\text { type }\end{array}$ & Company & Status \\
\hline \multicolumn{5}{|c|}{ ECM/fibroblasts } \\
\hline Sonidegib & SMO & \begin{tabular}{|l} 
Small \\
molecule
\end{tabular} & Novartis & \begin{tabular}{|l|} 
Phase II \\
(NCT01708174, \\
NCT01757327, \\
NCT02195973)
\end{tabular} \\
\hline \multicolumn{5}{|l|}{ Vasculature } \\
\hline Bevacizumab & VEGFA & Antibody & Genentech/Roche & $\begin{array}{l}\text { FDA-approved } \\
((\mathrm{BLA}) 125085)\end{array}$ \\
\hline Vandetanib & $\begin{array}{l}\text { VEGFRs, } \\
\text { PDGFRs, } \\
\text { EGFR }\end{array}$ & \begin{tabular}{|l} 
Small \\
molecule
\end{tabular} & AstraZeneca & $\begin{array}{l}\text { FDA-approved } \\
\text { ((NDA) 022405) }\end{array}$ \\
\hline Sunitinib & $\begin{array}{l}\text { VEGFRs, } \\
\text { PDGFRs, } \\
\text { FLT3, } \\
\text { CSF1R }\end{array}$ & \begin{tabular}{|l} 
Small \\
molecule
\end{tabular} & Pfizer & $\begin{array}{l}\text { FDA-approved } \\
\text { ((NDA) 021938) }\end{array}$ \\
\hline Axitinib & $\begin{array}{l}\text { VEGFRs, } \\
\text { PDGFRs, } \\
\text { KIT }\end{array}$ & \begin{tabular}{|l} 
Small \\
molecule
\end{tabular} & Pfizer & $\begin{array}{l}\text { FDA-approved } \\
\text { ((NDA) 022324) }\end{array}$ \\
\hline Sorafenib & $\begin{array}{l}\text { VEGFRs, } \\
\text { RAF, } \\
\text { PDGFRs, } \\
\text { KIT }\end{array}$ & \begin{tabular}{|l} 
Small \\
molecule
\end{tabular} & Bayer & $\begin{array}{l}\text { FDA-approved } \\
\text { ((NDA) 021923) }\end{array}$ \\
\hline Pazopanib & $\begin{array}{l}\text { VEGFRs, } \\
\text { PDGFRs, } \\
\text { KIT }\end{array}$ & \begin{tabular}{|l} 
Small \\
molecule
\end{tabular} & GlaxoSmithKline & $\begin{array}{l}\text { FDA-approved } \\
\text { ((NDA) 022465) }\end{array}$ \\
\hline Cabozantinib & $\begin{array}{l}\text { VEGFR2, } \\
\text { RET, MET }\end{array}$ & $\begin{array}{l}\text { Small } \\
\text { molecule }\end{array}$ & Exelixis & $\begin{array}{l}\text { FDA-approved } \\
\text { ((NDA) 023756) }\end{array}$ \\
\hline Ziv-aflibercept & $\begin{array}{l}\text { VEGFA, } \\
\text { VEGFB, } \\
\text { PIGF }\end{array}$ & $\begin{array}{l}\text { Receptor-Fc } \\
\text { fusion }\end{array}$ & Regeneron & $\begin{array}{l}\text { FDA-approved } \\
\text { ((BLA) 125418) }\end{array}$ \\
\hline AMG 386 & ANG2 & $\begin{array}{l}\text { RP-Fc } \\
\text { fusion } \\
\text { protein }\end{array}$ & Amgen & $\begin{array}{l}\text { Phase III } \\
\text { (NCT01204749, } \\
\text { NCT01493505, } \\
\text { NCT01281254) }\end{array}$ \\
\hline Parsatuzumab & EGFL-7 & Antibody & Genentech/Roche & $\begin{array}{l}\text { Phase II } \\
\text { (NCT01399684, } \\
\text { NCT01366131) }\end{array}$ \\
\hline
\end{tabular}




\begin{tabular}{|c|c|c|c|c|}
\hline Enoticumab & DLL4 & Antibody & Regeneron & \begin{tabular}{|l|l|} 
Phase I \\
(NCT00871559) \\
\end{tabular} \\
\hline Demcizumab & DLL4 & Antibody & OncoMed & $\begin{array}{l}\text { Phase I } \\
\text { (NCT00744562, } \\
\text { NCT01189968, } \\
\text { NCT01189942, } \\
\text { NCT01189929) }\end{array}$ \\
\hline Nesvacumab & ANG2 & Antibody & Regeneron & $\begin{array}{l}\text { Phase I } \\
\text { (NCT01271972 } \\
\text { NCT01688960 } \\
\text { NCT01997164) }\end{array}$ \\
\hline \multicolumn{5}{|l|}{ Immune } \\
\hline Ipilimumab & CTLA-4 & Antibody & \begin{tabular}{|l} 
Bristol-Myers \\
Squibb
\end{tabular} & $\begin{array}{l}\text { FDA-approved } \\
\text { ((BLA) 125377) }\end{array}$ \\
\hline Sipuleucel-T & PAP & DC vaccine & Dendreon & $\begin{array}{l}\text { FDA-approved } \\
((\mathrm{BLA}) 125197)\end{array}$ \\
\hline Aldesleukin & IL-2 & $\mathrm{RP}$ & Prometheus & $\begin{array}{l}\text { FDA-approved } \\
((\text { BLA) 103293) }\end{array}$ \\
\hline IFNa-2b & $\begin{array}{l}\text { IFN- } \alpha \\
\text { receptor }\end{array}$ & RP & Merck & $\begin{array}{l}\text { FDA-approved } \\
((B L A) 103132)\end{array}$ \\
\hline MK-3475 & PD1 & Antibody & Merck & $\begin{array}{l}\text { Phase III } \\
\text { (NCT01866319) }\end{array}$ \\
\hline Nivolumab & PD1 & Antibody & $\begin{array}{l}\text { Bristol-Myers } \\
\text { Squibb }\end{array}$ & $\begin{array}{l}\text { Phase III } \\
\text { (NCT01642004, } \\
\text { NCT01668784, } \\
\text { NCT01673867, } \\
\text { NCT01721746, } \\
\text { NCT01721772, } \\
\text { NCT01844505) }\end{array}$ \\
\hline Nivolumab & OX40 & Antibody & $\begin{array}{l}\text { Bristol-Myers } \\
\text { Squibb and } \\
\text { PPMC }\end{array}$ & $\begin{array}{l}\text { Phase III } \\
\text { (NCT01642004, } \\
\text { NCT01668784, } \\
\text { NCT01673867, } \\
\text { NCT01721746, } \\
\text { NCT01721772, } \\
\text { NCT01844505) }\end{array}$ \\
\hline MPDL3280A & PDL1 & Antibody & Genentech/Roche & \begin{tabular}{|l|} 
Phase II \\
(NCT01846416)
\end{tabular} \\
\hline PLX3397 & $\begin{array}{l}\text { KIT, CSF1R, } \\
\text { FLT3 }\end{array}$ & $\begin{array}{l}\text { Small } \\
\text { molecule }\end{array}$ & Plexxikon & $\begin{array}{l}\text { Phase II } \\
\text { (NCT01349036) }\end{array}$ \\
\hline BMS-663513 & $\begin{array}{l}\text { CD137 } \\
(4-1 B B)\end{array}$ & Antibody & \begin{tabular}{|l|} 
Bristol-Myers \\
Squibb
\end{tabular} & \begin{tabular}{|l|} 
Phase II \\
(NCT00612664)
\end{tabular} \\
\hline Blinatumomab & CD3 and & Bi-specific & Amgen & Phase II \\
\hline
\end{tabular}




\begin{tabular}{|c|c|c|c|c|}
\hline & CD19 & $\mathrm{scFv}$ & & $\begin{array}{l}\text { (NCT01741792, } \\
\text { NCT01466179, } \\
\text { NCT01207388, } \\
\text { NCT01471782, } \\
\text { NCT00560794, } \\
\text { NCT01209286) }\end{array}$ \\
\hline AMG 820 & CSF1R & Antibody & Amgen & $\begin{array}{l}\text { Phase I } \\
\text { (NCT01444404) }\end{array}$ \\
\hline AMP-224 & PD1 & Antibody & GlaxoSmithKline & $\begin{array}{l}\text { Phase I } \\
\text { (NCT01352884) }\end{array}$ \\
\hline TRX-518 & GITR & Antibody & GITR, Inc. & $\begin{array}{l}\text { Phase I } \\
\text { (NCT01239134) }\end{array}$ \\
\hline IMC-CS4 & CSR1R & Antibody & ImClone/Eli Lilly & $\begin{array}{l}\text { Phase I } \\
\text { (NCT01346358) }\end{array}$ \\
\hline CP-870,893 & CD40 & Antibody & Pfizer & $\begin{array}{l}\text { Phase I } \\
\text { (NCT00711191, } \\
\text { NCT01008527, } \\
\text { NCT00607048, } \\
\text { NCT01456585, } \\
\text { NCT01103635) }\end{array}$ \\
\hline $\begin{array}{l}\text { IMC-CS4/ } \\
\text { LY3022855 }\end{array}$ & CSF1R & Antibody & Eli Lilly & $\begin{array}{l}\text { Phase I } \\
\text { NCT01346358 } \\
\text { NCT02265536 }\end{array}$ \\
\hline Carlumab & CCL2 & Antibody & $\begin{array}{l}\text { Centocor } \\
\text { Research \& } \\
\text { Development }\end{array}$ & $\begin{array}{l}\text { Phase II } \\
\text { NCT00992186 }\end{array}$ \\
\hline MNRP1685A & Neuropilin-1 & Antibody & Genentech & $\begin{array}{l}\text { Phase I } \\
\text { NCT00954642 } \\
\text { NCT00747734 }\end{array}$ \\
\hline Clazakizumab & IL-6 & Antibody & $\begin{array}{l}\text { Bristol-Myers } \\
\text { Squibb }\end{array}$ & $\begin{array}{l}\text { Phase I } \\
\text { NCT02015520 }\end{array}$ \\
\hline Olokizumab & IL-6 & Antibody & $\begin{array}{l}\text { UCB Japan } \\
\text { UCB Pharma }\end{array}$ & $\begin{array}{l}\text { Phase II } \\
\text { NCT01463059 } \\
\text { NCT01533714 }\end{array}$ \\
\hline
\end{tabular}

References listed in the status column pertain to the molecule as a TME-modifying agent, either the FDA application, where approved, or the national clinical trial identification of the oncology trial in the latest phase is listed (note that in some cases the drug may also be tested or approved for an indication for which it acts directly on the tumor cell compartment, which will not be referenced here). ANG2, angiopoietin 2; BLA, biological license application; CCL2, chemokine C-C motif ligand 2; CSF1R, colony stimulating factor 1 receptor; CTLA-4, cytotoxic 
T-lymphocyte-associated antigen 4; DC, dendritic cell; DLL4, delta-like 4; ECM, extracellular matrix; EGFL-7, epidermal growth factor like 7; EGFR, epidermal growth factor receptor; FDA, Food and Drug Administration; FLT3, Fms-like tyrosine kinase 3; GBM, glioblastoma multiforme; GITR, glucocorticoid-induced TNFR-related; IFN, interferon; IL-2, interleukin 2; MMP, matrixmetalloproteinase; NCT, national clinical trial; NDA, new drug application; PAP, prostatic acid phosphatase; PD-1, programmed death-1; PDAC, pancreatic ductal adenocarcinoma; PDGFR, Platelet-derived growth factor receptor; PDL1, programmed death ligand 1; PPMC, Portland Providence Medical Center; RP, recombinant peptide; ScFv, single-chain Fv; SMO, smoothened; VEGF, vascular endothelial growth factor; VEGFR, vascular endothelial growth factor receptor.

Table adapted from reference 5 of this article (Junttila and de Sauvage) with permission from Nature, copyright 2013 and reference 49 (Ruffell and Coussens) with permission from Cancer Cell, copyright 2015. Note, agents that either failed to be effective in clinical trials or have been officially terminated are removed from the current list. 